\title{
HOMBRES, IDEASS Y HECHOS
}

\section{Divagaciones alrededor de la poesía}

III. El POEMA. TIEMPO DE GESTACIÓN Y CREACIÓN.

N el número 55 de Atenea (páginas 476 a 493) se publicó una conferencia que R. Meza Fuentes leyó a los estudiantes de Filosofía del Instituto Pedagógico de la Universidad de Chile. En dicha conferencia, titulada La creación artística según Paul Valéry, aparecen citas extractadas de una conferencia de este escritor y traducidas por el conferenciante. Dichas citas presentan algunas curiosas observaciones sobre la creación poética, y una de las más interesantes, para mí, es aquella que se refiere (pág. 490) a lo que yo llamaría tiempo de gestación y creación del poema. Doy esta denominación a ese tiempo sin medida que se inicia en el momento en que una sensación o una idea hieren la sensibilidad del artista, despertando en su imaginación diversas resonancias, y que termina cuando el poeta concluye su labor poética, o a aquél que empieza en el punto en que un motivo poético puro, es decir, no provocado por causas exteriores, sino surgido de las sensaciones interiores-espirituales, fisiológicas, cenestésicas, de la fersonalidad intrínseca del hombre-comienza a vibrar en alguna parte - ¿en qué parte: subconsciente o inconsciente?-del artista, y que fina, como en el caso anterior, al rematar el poema. Este tiempo de gestación de la obra poética, que es lo que yo he llamado el fenómeno prístino de la poesía, la poesía misma, aparece muy claramente diferenciado en las observaciones de Valéry. 
Copiemos aquella cita, distribuyendo ese tiempo en cuatro períodos:

He aquí un recuerdo; he aquí lo que encuentro en el origen de cierto poema que escribí hace algunos años. Estaba un día obsesionado por un ritmo que se hizo de repente sensible a mi espíritu, después de un tiempo durante el cual no tenía sino una semi-conciencia de esta actividad lateral. Ese ritmo se imponía a mi espíritu como una exigencia. Me parecía que quería tomar cuerpo, llegar a la perfección de su ser.

Dije en mi primer artículo (1) que la poesía obraba, a veces, en el hombre como el viento en la flauta, llenándolo de su flúido, hasta que, colmándolo, provocaba en él la idea poética o el estado poético. Esta observación de Valéry confirma mis palabras. Es el primer período de la manifestación poética, el primero que el hombre puede percibir, pues hay otro, anterior, que el hombre no percibe. Es aquél sobre el cual no tenemos sino nociones vagas y que suponemos sólo por hipótesis; un período que podríamos llamar cero: el período de la elaboración de ese ritmo.

En el caso de Valéry vemos cómo el f́lúido ha llenado al poeta y cómo exige ser expresado. Esto es la consecuencia de la plenitud de que el artista está invadido. Bajando hacia peldaños inferiores de los fenómenos fisiológicos, vemos que todo órgano en estado de plenitud exige ser Iibrado de aquello que lo llena. $\mathrm{Y}$ con esto no pretendo comparar la poesía a ninguna función fisiológica; sólo quiero hacer notar que el automatismo, aun en funciones muy diferentes, presenta los mismos caracteres mecánicos y que entre un fenómeno fisiológico de orden inferior y uno psicológico de orden superior, no hay sino una diferencia de calidad. El ritmo llena el órgano que lo produce y exige ser emitido, realizado.

Tenemos, pues, el primer período. Veamos el segundo:

Pero no podía precisarse en mi conciencia sino influenciándose o asimilando en alguna forma elementos verbales: sílabas, palabras, y estas sílabas y estas palabras estaban sin duda a punto de formarse, determinadas por su valor y sus atracciones musicales. Eran un estado de esbozo, un estado infantil en que forma y materia se distinguían poco la una de la otra, pues la forma rítmica constituía en ese momento la única condición de admisión o emisión. Tal fué la segunda aproximación. La primera estaba constituida por el ritmo desnudo, la percusión pura y simple.

Esta cita de Valéry constituye un ejemplo de lo que he llamado inspiración espontánea. El proceso está claro y lógico.

(1) Núm. 64 de Atenea.

Atenea.-5 
Hasta ese momento, segundo periocio, el artista no sake qué cirección lleva ese ritmo y cuál es la representación que llegatá a tener. Nace y el poeta no sabe por qué nace; se hace presente en su espíritu, suena, avisando de este modo su presencia, y como el poeta no sabe cómo alim entarlo, de modo que llegue a tener envoltura, forma, expresión, o como, por otra parte, el poeta, intencionadamente o temiendo desvirtuar el valor de espontaneidad del ritmo, no quiere agregarle palabras que tal vez no correspondieran a la significación que ese ritmo trae consigo, espera, lo deja. Pero entonces el ritmo trabaja por sí solo y ensaya reunir sílabas, palabras, eligiendo aquellas que puedan servirle de digno vehículo y que se equilibren entre sí por su valor y sus atracciones musicales. Procede asimilando elementos que, aunque desemejantes a él, son los únicos que pueden expresarlo. Se ha comparado muchas veces la poesía a la música y la comparación no es del todo inexacta, pues ambas aparecen en el espíritu del hombre en igual forma: por ritmos. Pero la música tiene sobre la poesía una ventaja grande: el medio de expresión. La escala, con sólo constar de siete notas, tiene infinitas variaciones y corresponde, más que la palabra, al espíritu del ritmo. La palabra tiene siempre un significado definitivo y sólo se puede usar para representar ese significado; hay que relacionarlas de modo lógico, que una corresfonda a la otra, y esa correspondencia se determina y se liga por una serie de signos auxiliares. Usar las palabras nada más que por su sonido, con el deseo de expresar con ellas el ritmo que se siente-cosa que se puede muy bien hacer-, es caer en la oscuridad más profunda, en la incomprensión más absoluta. Cierta poesía nueva tiende a ello y, entre nosotros, Neruda ha hecho algunos ensayos. Pero ya se ha visto el resultado: los lectores quieren, más que oír el ritmo del poeta, comprender las palabras de que el poeta se vale para manifestar el ritmo. No se satisfacen con la música de las palabras. Están acostumbrados a otra cosa. Pero, en esa forma, aquella cierta poesía nueva se acerca a la música. Hay poemas que debieron escribirse con notas, que no se desvirtúan nunca como tales y que tienen más propiedad que las palabras para expresar un ritmo interior.

Pero el ritmo interior del poeta está fatalmente constreñido a servirse de palabras, y las busca, las selecciona como si poseyera espíritu selectivo, cuando en verdad no posee más que sonido; es un sonido que busca otros sonidos para completarse y llegar a ser. No encuentra más que palabras a su alcance y las toma. Lamennais decía: 
El lenguaje, medio de expresión de la poesía, no es la poesía misma (1).

Pero pongamos atención. El verso está por cuajarse:

Sucedió en seguida que, por una especie de despertar de la conciencia o de una extensión brusca de su dominio-extensión cualitativa, bien entendido, crecimiento del número de exigencias independientes-, se produjo una sustitución de sílabas y palabras provisionalmente llamadas y cierto verso "inicial se encontró no solamente terminado sino que me pareció, como el efecto de una necesidad, imposible de modificar.

Valéry habla aquí de conciencia y esto nos sorprende. La palabra conciencia está de más. Conciencia significa conocimiento y el autor de Variété no tuvo conciencia (o conocimiento) del verso hasta que éste no estuvo formado. No pudo el verso ser fruto de ella ni ella influir en su creación, aunque su dominio se hubiera extendido cualitativa o cuantitativamente. Todo lo que ha sucedido hasta este momento ha sucedido fuera de la conciencia; ésta no ha hecho más que mirar lo que sucedía. Es un esfectador que debe, bajo fena de convertir el verso o el poema en una obra didáctica o de otra índole inferior, permanecer inmóvil. La conciencia es al foema lo que el simple erudito a la obra artística: un esfectador, un comentador.

El mismo Meza Fuentes (pág. 488) dice:

El verso carece de argumento, de significado, de traducción.

Y la conciencia no puede producir nada que no tenga significado, traducción. ¿Por qué, entonces, conciencia? ¿Por qué no imaginación? Es lástima que no conozcamos el poema de que habla Valéry. Su análisis nos hubiera aclarado mucho esta tercera cita.

Pero dejemos a un lado la conciencia, que nada tiene que hacer en la poesía, y prosigamos. Siguiendo la línea que hemos trazado en estos artículos, sobre las relaciones de la poesía y la imaginación, podemos suponer que al finar el segundo período, aquel en que algunas sílabas y palabras se unían al ritmo, la imaginación creadora entró en juego y combinando el ritmo con las sílabas y las palabras y agregando lo que a aquél y a éstas les faltaba, produjo un verso perfecto. Es muy posible que la acción que Valéry atribuye a la conciencia no fuera sino un llamado de ésta a la imaginación, llamado hecho en forma

(1) Recordemos que Lamennais era creyente y que con estas palabras quería significar lo que a él. ccmo creyente, le interesaba. Pero nosotros, haciendo caso omiso de la significación que él les daba, las utilizamos para expresar lo ue nos inter esa significar. 
inaprehensible para los sentidos del poeta, el cual, ignorándolo, atribuyó a la primera la obra de la segunda, obra que, por otra parte, Valéry no explica ni puede explicar, ya que al decir:

por una especie de despertar de la conciencia o de una extensión brusca de su dominio,

no dice nada concreto. Esa extensión brusca podría ser el llamado, que Valéry ha confundido con una manifestación artística de la conciencia. Del llamado al verso ha existido tan breve espacio de tiempo, tan simultáneos han sido ambos, que no ha dejado al poeta tiempo alguno para observar de dónde surgía verdaderamente el verso.

En todo caso, tenemos ya un verso y con él todo el proceso de la inspiración espontánea y casi un ejemplo de poesía pura, libre, llegada al conocimiento del poeta en forma desconocida y sorpresiva. Decimos casi un ejemplo de poesía pura porque, en printer lugar, no conocemos el poema ni el verso recién nacido, y en segundo, porque al hablar de poesía pura debe interponerse siempre un casi, ya que ella, en su más estricto sentido, no existe, en la mayoría de los casos, sino hasta el momento en que la palabra se incorpora al rịtmo; en algunos existe más allá, pero siempre que las palabras que se unen al ritmo le añadan sólo lo que al ritmo corresponde, es decir, musicalidad; si las palabras quieren usarlo para exprestar una realidad cualquiera, la poesía pura desaparece. Debido a esto, la poesía pura no aparece sino en versos aislados, en aquellos que nacieron perfectos y que se dejaron tales como nacieron: frutos de la inspiración espontánea, de la felicidad espontánea, que dice Valéry. Música pura, sin expresión alguna, tanto más pura cuanto menos expresión ajena tiene.

Esos versos puros, como el que acaba de formarse en la cita de Valéry, sirven de base al poema, el cual se construye luego alrededor de él: es la materia prima, el punto de partida, la cifra que se da a la imaginación reproductora. Después viene el Gltimo período:

Pero este verso exigía una continuación musical y lógica. El dedo estaba en el engranaje. Por desgracia para el poeta, la gozosa coincidencia no prosigue continuamente y hay necesidad de apelar al trabajo y a los artificios para imitar lo que uno fué hace un instante. La razón de esta interminencia de la felicidad espontánea es muy sencilla: en el lengua;e el sonido y el sentido no están unidos sino por una convención.

He subrayado la palabra lógica para evitar que se le dé una interpretación que no tiene. La palabra lógica indica ahí que 
la continuación que exige ese verso debe estar en armonía con él, seguir su caciencia, su tono, el tema que el verso entrega al poeta y a la imaginación, porque ese verso no es sino el motivo poético a desarrollar.

Ese motivo poético se desarrolla del modo que ya hemos tratado de describir en artículos anteriores: por el deseo, por la imaginación, por la meditación, por la insistencia, por lo que se llama trabajo, en fin; escribiendo y recitando una y otra vez el verso, hasta que otro nuevo, esta vez provocado, venga a unirse al primero, y otros a estos dos, hasta terminar el poema, poema cuya gestación y creación ha pasado por los cinco períodos que hemos analizado, o sea:

Período cero: elaboración del ritmo.

1. ${ }^{\circ}$ Aparición del ritmo.

2. Manifestaciones autónomas del ritmo.

3. ${ }^{\circ}$ Formación del verso inicial o matriz.

4. ${ }^{\circ}$ Creación del poema.

El período cero lo hemos estudiado en la primera y segunda parte de estas divagaciones.-MANUEL ROJAS.

\section{El espíritu de la nueva Suiza}

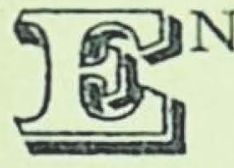

una larga permanencia en Lausana, conversancio con prestantes hombres de ciencia, leyendo periódicos, observando, he querido tracear lo que es el espíritu de la nueva Suiza, en estos años europeos de reconstrucción moral y material.

Presentaba brillante ocasión para este género de estudios la votación popular, el referendum, que ha tenido lugar en los primeros clías del reciente mes de Abril. Esta democracia sana y activa había de aprobar o rechazar una ley que prohibe la fabricación de alcohol de manzana. Ahora bien, los políticos y los predicadores, los moralistas y los periodistas habían intervenido en el debate con ardimiento. Se decía y se demostraba que el consumo de alcohol enflaquecía a la raza y producía una secuela de males: degeneración, cretinismo, deformaciones de varia especie. Una nación de aldeanos, gravemente ligada a la tierra, fuerte y laboriosa iba siendo atrozmente inficionada. Dos intereses combatían, uno, de orden económico, el de las industrias; y otro, de orden moral, el de la salud de la raza. Pues bien, la ética ha triunfado. Serán restringidos la producción y el consumo del alcohol. 